\title{
Aspectos ultrassonográficos dos componentes umbilicais de bezerros da raça Holandesa durante o processo de involução fisiológica
}

\author{
[Ultrasonographic aspects of umbilical components of Holstein calves during the physiological \\ involution process] \\ J.A. Bombardelli ${ }^{1}$, C.H. Seino ${ }^{1}$, G.A. Reis ${ }^{1}$, C.L. Shecaira ${ }^{1}$, M.R. Azedo ${ }^{2}$, F.J. Benesi ${ }^{1}$ \\ ${ }^{1}$ Universidade de São Paulo - São Paulo, SP \\ ${ }^{2}$ Universidade Metropolitana de Santos - Santos, SP
}

\begin{abstract}
RESUMO
Afecções umbilicais são comumente encontradas nos bezerros durante o período neonatal, podendo ocasionar graves complicações. Seu diagnóstico muitas vezes não é preciso pela palpação abdominal, sendo a ultrassonografia um valioso exame complementar, pois permite precisão na localização e na extensão das onfalopatias intra-abdominais. Diante disso e da raridade de pesquisas com estabelecimento de padrões ultrassonográficos do umbigo, o presente estudo propôs padronizar os aspectos das imagens ultrassonográficas dos componentes umbilicais em decorrência de sua involução. Foram avaliados 23 bezerros Holandeses, do nascimento até os 30 dias de vida, em cuja região umbilical se usou como antisséptico tintura de iodo em diferentes concentrações. Os resultados evidenciaram que veia e artérias umbilicais perdem suas características de vasos, assumindo aspecto de ligamento por proliferação de tecido fibroso. Nesse processo, o tecido fibroso, inicialmente presente na região interna da parede do vaso, segue, com a involução, em direção à luz, sendo observado mais precocemente em porções dos vasos mais distantes do umbigo externo, não havendo distinção de comportamento determinada pela antissepsia. Para aproveitamento do exame ultrassonográfico, é importante o conhecimento dos aspectos das imagens durante o processo de involução dos componentes umbilicais, de acordo com cada fase, sendo assim possível o diagnóstico das diferentes alterações nessas estruturas.
\end{abstract}

Palavras-chave: bezerro, componentes umbilicais, ultrassonografia

\begin{abstract}
Umbilical diseases of calves happen during neonatal period and may lead to severe complications. The diagnosis is usually through abdominal palpation although it is not very accurate, thus ultrasound provides a valuable complementary exam to establish a precise diagnosis of location and extent of intraabdominal umbilical diseases. Given those facts and the lack of established standards for umbilical ultrasound imaging the present study proposal was to standardize the physiological aspects of umbilical components during involution. Ultrasound images were obtained for 23 Holstein calves, from birth until 30 days of life. Iodine tincture of different concentrations was used for umbilical region antisepsis. Results show that umbilical vein and arteries lose their vessel characteristics, becoming similar to ligament, due to the proliferation of fibrous tissue. The growth pattern of the fibrous tissue was from the vessel walls growing toward vascular lumen. The involution process begins at the most distant part and did not vary with antiseptic concentrations. To obtain a reliable ultrasound exam it's important to know the aspects of imaging patterns according to each phase of umbilical involution, thus leading to an accurate diagnosis of structural variations and umbilical diseases.
\end{abstract}

Keywords: calves, umbilical components, ultrasonography

Recebido em 4 de outubro de 2016

Aceito em 5 de julho de 2017

E-mail: juliana.bombardelli@usp.br 


\section{INTRODUÇÃO}

O rebanho bovino brasileiro representa atualmente o segundo maior rebanho do mundo (Hyberuille Neto, 2014), o que demostra a grande importância da bovinocultura no país. Dentro de um sistema de produção, os bezerros são os mais susceptíveis às doenças, sendo o manejo neonatal relevante para seu futuro desempenho como produtores de carne ou leite. Os neonatos precisam se adaptar às grandes diferenças ambientais a que são submetidos fora do útero, sendo, portanto, a fase neonatal decisiva para a sua sobrevivência, uma vez que, particularmente, seu sistema imunológico encontra-se em desenvolvimento (Benesi, 1992). Logo após o nascimento, o fornecimento de colostro, no momento e em quantidade adequados, associado à desinfecção do umbigo, constitui cuidado que favorece a prevenção das doenças que acometem esses animais (Laender et al., 1984). Dentre essas doenças, merecem destaque as afecções umbilicais, que se desenvolvem geralmente durante suas três primeiras semanas de vida (Andrews, 1983), tendo a poliartrite como a mais frequente infecção secundária decorrente das onfalopatias (Riet-Correa, 2007).

Segundo Radostits et al. (2002), os problemas umbilicais são uma das mais importantes doenças em bezerros, chegando a $10 \%$ a mortalidade dos animais até oito meses em decorrência das onfalopatias e de suas complicações. Os microrganismos mais frequentes nas infecções umbilicais são muitas vezes isolados nos animais com bacteremia e septicemia, o que comprova que o umbigo é uma importante porta de entrada para agentes causadores de enfermidades características do período neonatal (Radostits et al., 2002; Rengifo et al., 2006).

O exame ultrassonográfico do umbigo e de seus componentes intra-abdominais é recomendado em animais com anormalidades palpáveis nessa região, persistência de úraco e infecções localizadas decorrentes de bacteremia, como a artrite séptica. A ultrassonografia é consagrada como um método não invasivo de visualização das alterações das estruturas abdominais em potros (Reef et al., 1988; Reef et al., 1989; Reef, 1991) e bezerros (Craig et al., 1986; Steiner et al., 1992), sendo considerada útil para a avaliação de estruturas umbilicais extraabdominais e intra-abdominais (Flöck, 2003). No entanto, é essencial o conhecimento prévio da aparência ultrassonográfica normal das estruturas para o total aproveitamento do exame.

Apesar de todos os benefícios apresentados com o uso da ultrassonografia na avaliação dos componentes umbilicais, são poucos os estudos relacionados a esse tema, especialmente em neonatos bovinos. Devido à escassez desses trabalhos e à grande importância das onfalopatias na criação de bezerros, foi proposto o objetivo deste estudo, que visa definir os padrões de imagens ultrassonográficas na involução fisiológica dos componentes umbilicais em bezerros Holandeses até os 30 dias de vida.

\section{MATERIAL E MÉTODOS}

Durante o estudo, foram avaliados 31 bezerros machos, da raça Holandesa, oriundos de propriedade leiteira localizada na cidade de Descalvado, estado de São Paulo e alojados na Clínica de Bovinos e Pequenos Ruminantes (CBPR) da Faculdade de Medicina Veterinária e Zootecnia da Universidade da São Paulo (FMVZ/USP), campus de São Paulo, desde o nascimento até os 30 dias de vida, com condições adequadas para seu conforto e desenvolvimento durante esse período (procedimento aprovado pela Comissão de Ética - Ceua/FMVZ/USP - protocolo número 2285150415). A desinfecção do umbigo foi realizada durante os três primeiros dias p.n., duas vezes ao dia, com tintura de iodo em concentrações de $2 \%$ em 16 animais e $5 \%$ em 15 , aleatoriamente.

Todos os bezerros foram examinados diariamente, sendo realizados exames físico geral e específico da região umbilical, para a possível identificação de alguma afecção que eliminasse o animal do estudo. $\mathrm{O}$ exame físico geral e a avaliação abdominal dos bezerros foram feitos conforme critérios estabelecidos por Dirksen et al. (1993) e Feitosa e Benesi (2014). O exame físico geral incluiu a avaliação do estado geral, das funções vitais, do grau de hidratação, da coloração das mucosas aparentes e das características das fezes.

Para o exame específico da região umbilical, seguiu-se o protocolo proposto por Figueirêdo (1999) e Dirksen et al. (2005), no qual era feita a 
inspeção e a palpação do umbigo externo com o animal em estação. A seguir, com o animal em decúbito lateral direito, foi realizada a palpação bimanual profunda da região abdominal, nos sentidos ventrodorso-cranial e ventrodorsocaudal ao umbigo externo, com a finalidade de descartar qualquer alteração dos componentes umbilicais intra-abdominais.

A fim de comprovar a higidez dos animais estudados, foram realizados hemogramas de todos os bezerros, com intervalos de cinco dias ao longo do período do estudo. As amostras coletadas em tubos com EDTA foram refrigeradas a $4^{\circ} \mathrm{C}$ e encaminhadas ao Laboratório Clínico de Rotina do Departamento de Clínica Médica da FMVZ-USP para realização de hemograma. As contagens de eritrócitos, de leucócitos e de plaquetas, a dosagem de hemoglobina, a avaliação do volume globular (hematócrito) e o cálculo dos índices hematimétricos absolutos (VCM, HCM e $\mathrm{CHCM}$ ), foram efetuados em contador eletrônico de partículas (BC-2800Vet ${ }^{\circledR}$, Mindray Medical Brazil Limited, São Paulo, SP), sendo as referências dos valores para o eritrograma (Benesi et al., 2012a) e leucograma (Benesi et al., 2012b) baseadas nos valores para bezerros com até 30 dias p.n.. Além disso, esses neonatos foram analisados quanto à adequada transferência de imunidade passiva a partir de duas coletas de sangue intervaladas por 48 horas, realizadas até 72 horas de vida, para obtenção do soro, que foi submetido à quantificação da taxa de proteína total (PT), de globulinas e da atividade sérica enzimática da gamaglutamiltransferase (GGT) por refratometria e por meio de analisador automático bioquímico (Randox ${ }^{\circledR}$ RX Daytona).

A avaliação ultrassonográfica da região abdominal foi realizada com a finalidade de se estudarem os componentes umbilicais e sua involução fisiológica dos bezerros, sendo os exames realizados em períodos predeterminados ao longo dos 30 dias de vida do animal (primeiro, segundo, terceiro, quarto, quinto, $10^{\circ}$, $15^{\circ}, 17^{\circ}, 20^{\circ}, 25^{\circ}$ e $30^{\circ}$ dia pós- nascimento). Para essa finalidade, foi utilizado aparelho de ultrassom modelo M5Vet (Mindray Medical Brazil Limited, São Paulo, SP), com transdutor linear mantido com a frequência de $7,5 \mathrm{MHz}$. Os animais foram mantidos em decúbito lateral direito e as posições avaliadas localizavam-se entre a cartilagem xifoide e a pelve, conforme proposto por Lischer e Steiner (1993) e Buczinski (2002), de acordo com a Fig. 1.

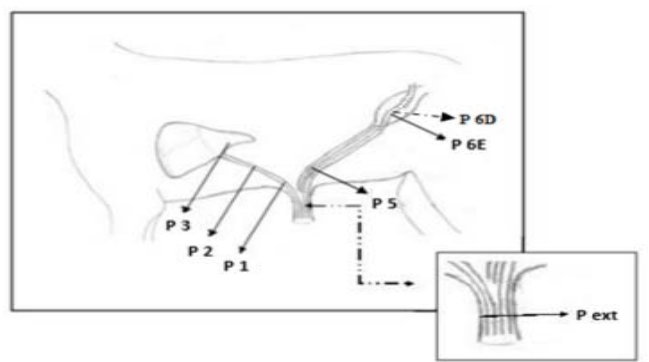

Figura 1. Posições dos componentes umbilicais avaliadas durante o exame ultrassonográfico de bezerros da raça Holandesa, durante o primeiro mês de vida. P ext -posição externa - região média do umbigo externo; P 1 - posição 1 região imediatamente cranial ao anel inguinal interno; P 2 - posição 2 - região mediana ao anel inguinal interno e o fígado; P 3 - posição 3 margem caudoventral do fígado; P 5 -posição 5 região imediatamente caudal ao anel inguinal interno; P 6D - posição 6 direita - região lateral direita à vesícula urinária; P $6 \mathrm{E}$ - posição 6 esquerda - região lateral esquerda à vesícula urinária.

\section{RESULTADOS E DISCUSSÃO}

Os resultados dos exames laboratoriais e dos exames físicos seriados constataram a higidez dos neonatos durante o período de estudo, bem como a adequada transferência de imunidade passiva colostral. Foram obtidas as imagens ultrassonográficas dos componentes umbilicais nos momentos e nas posições propostos. Comparando-se os resultados obtidos nos animais estudados, as ultrassonografias avaliadas foram similares durante o processo de involução fisiológica dos componentes do cordão umbilical, em cada momento determinado e independentemente da concentração do antisséptico utilizado, tendo poucas variações para cada indivíduo. Em algumas das imagens, independentemente da posição ou do momento do exame, foi possível a visualização de linha hiperecoica presente entre a parede e o lúmen dos vasos, sendo possivelmente o ponto do início da formação de tecido fibroso, já que, durante o processo de involução fisiológica dos componentes umbilicais, estes se transformam progressivamente em ligamentos e seu aspecto 
ultrassonográfico modifica-se em decorrência desse processo.

$\mathrm{Na}$ avaliação da posição P ext (Fig. 2), puderam ser visualizados dois vasos com formato arredondado ou elíptico na maior parte dos animais. Destaca-se, na rara literatura sobre o assunto, que as artérias umbilicais e o úraco se retraem logo após o parto para o interior da cavidade abdominal $\mathrm{e}$ as veias umbilicais permanecem fixadas ao anel umbilical (Figueirêdo, 1999). Porém, com o uso de recurso ultrassonográfico, tal como foi constatado por Sturion et al. (2013), e no presente estudo, as artérias podem ser visualizadas próximas ao anel umbilical durante todo o processo de involução desses componentes vasculares.

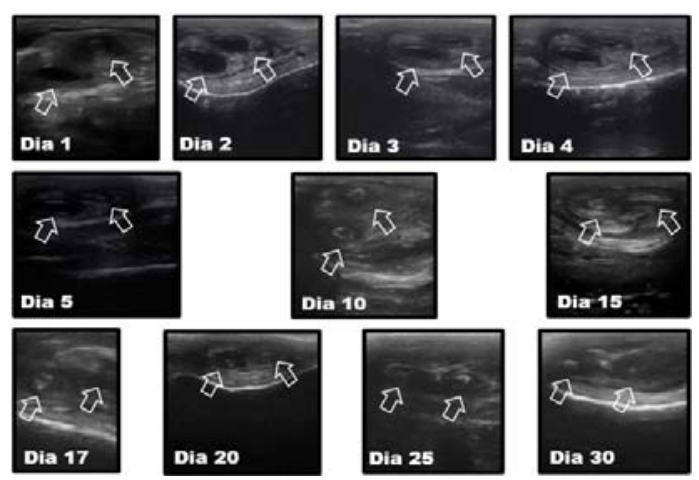

Figura 2. Acompanhamento ultrassonográfico da involução dos vasos umbilicais, na posição externa, em bezerros Holandeses, do primeiro ao $30^{\circ}$ dia de vida.

Pode ser observado que os componentes do umbigo externo, que inicialmente apareciam com uma imagem com parede hipoecoica e lúmen anecoico, gradativamente foram apresentando o lúmen preenchido por conteúdo que no início é heterogêneo e, ao fim do processo involutivo, torna-se homogêneo e hiperecoico, caracterizando a proliferação de tecido conjuntivo, com os componentes assumindo as características de ligamentos (Seino, 2014). Verificou-se que não foi mais possível se observar o lúmen anecoico na maioria dos animais após 15 a 20 dias p.n., sendo que o centro da estrutura umbilical tornou-se hiperecoico e homogêneo, com parede hipoecoica.

Partindo-se do umbigo externo, pôde-se observar as veias umbilicais a poucos centímetros do anel de entrada no abdômen, no sentido dorsocranial, ocorrendo, então, sua anastomose, notando-se o exato ponto de união dessas duas estruturas (Fig. 3). É possível, com certa facilidade na maior parte dos animais, principalmente nos primeiros cinco dias de vida, avaliar a veia em sua plenitude, desde a entrada no abdômen até sua chegada e entrada no fígado. Em geral, até o exame realizado no $10^{\circ}$ dia de vida dos animais, foi possível acompanhá-la na totalidade de seu trajeto, mas, assim como destacado por Sturion et al. (2013), após a segunda semana de vida, isso se tornou mais difícil. Lischer e Steiner (1993) e Watson et al. (1994), que avaliaram raças taurinas, tiveram maior dificuldade de individualização dessas estruturas, mesmo em períodos anteriores, provavelmente devido à qualidade e à resolução do aparelho ultrassonográfico mais antigo que usaram, em geral com uma menor possibilidade de recursos para melhoria da qualidade da imagem e facilitação do exame. No presente estudo, essa dificuldade também era maior quando o exame era realizado próximo à mamada do animal, pois o conteúdo e a distensão abomasal dificultavam essa visualização. Também, quanto a essa questão, levantada por Sturion et al. (2013), com os quais se concorda, o exame ultrassonográfico realizado pelos autores Lischer e Steiner (1993) e Watson et al. (1994) foi efetuado com os bezerros em estação, e talvez essa postura tenha dificultado, para esses autores, o exame e a visualização das estruturas umbilicais.
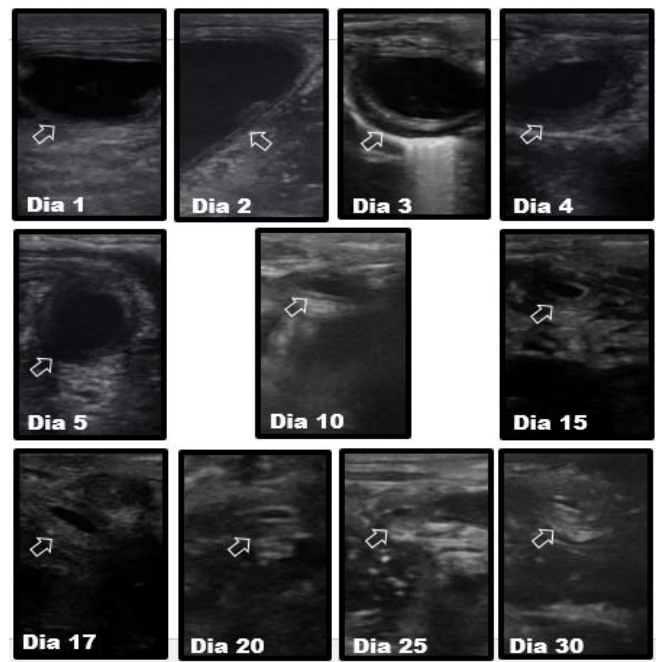

Figura 3. Acompanhamento ultrassonográfico da involução da veia umbilical (setas), na posição 1 , em bezerros Holandeses, do primeiro ao $30^{\circ}$ dia de vida. 
Durante o registro das imagens ultrassonográficas da veia umbilical (Fig. 3, 4 e 5), a posição que apresentou maior dificuldade para a obtenção foi a P 3, que é a mais distante do umbigo externo e mais próxima ao fígado. Essa dificuldade era encontrada, em particular, quando não havia a possibilidade de segui-la a partir da posição $\mathrm{P} 2$, situação em que não havia um ponto de referência para encontrá-la. Pode ser verificado que, no primeiro e no segundo dias de vida do animal, principalmente nas posições $\mathrm{P}$ 2 e P 3, a parede da veia era mais hipoecoica que aquela a partir do terceiro dia, e muitas vezes essa parede era difícil de ser visualizada nesses primeiros dias. Tal fato também foi constatado em pesquisas anteriores com bezerros Holandeses, em que a parede da veia no primeiro dia é descrita como discreta e raramente visualizada. Sturion et al. (2013) afirmam que a ecogenicidade da parede nos animais da raça Nelore tem tendência a aumentar e a luz do vaso a reduzir com a evolução da idade. Nos animais Holandeses estudados nesta pesquisa, foi observado que ecogenicidade da parede tende a aumentar, em geral, somente até o segundo ou terceiro dia, e a luz do vaso também reduz gradativamente, como observado nos bezerros da raça Nelore. Essa redução na luz do vaso ocorre de forma progressiva e em sentido caudal. Assim, a primeira posição em que não foi mais observada a luz do vaso foi a P 3 , seguida da P 2 $\mathrm{e}$, por último, a P 1. Diferentemente do que foi observado em bezerros da raça Nelore por Sturion et al. (2013), a veia apresentou-se com lúmen maior na avaliação mais próxima ao anel umbilical, concordando com o observado em outros trabalhos com raças taurinas.

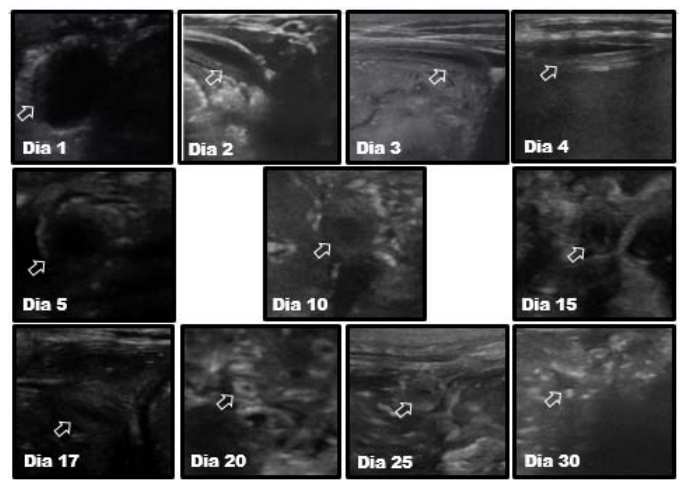

Figura 4. Acompanhamento ultrassonográfico da involução da veia umbilical (setas), na posição 2, em bezerros Holandeses, do primeiro ao $30^{\circ}$ dia de vida.

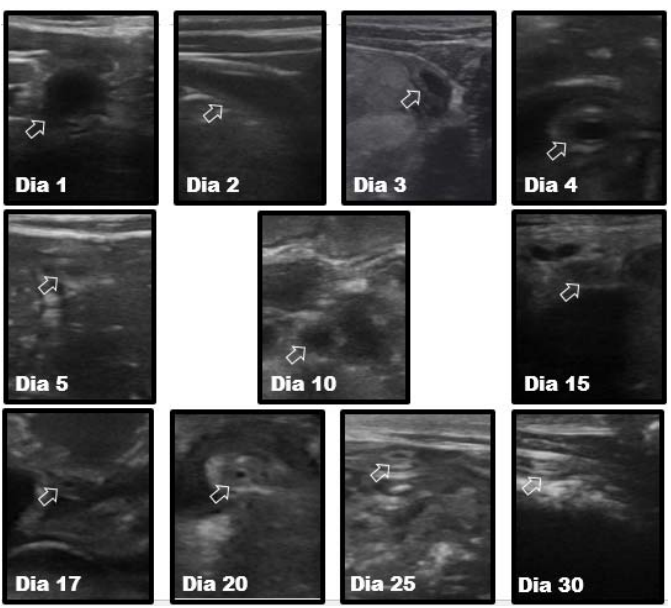

Figura 5. Acompanhamento ultrassonográfico da involução da veia umbilical (setas), na posição 3, em bezerros Holandeses, do primeiro ao $30^{\circ}$ dia de vida.

Sturion et al. (2013) constataram, em seu estudo com animais de raça zebuína, que a veia umbilical pode ser vista em qualquer ponto de seu trajeto contendo a parede hiperecoica e o lúmen anecoico. No presente estudo, de modo diverso, foi observada a parede como uma estrutura hipoecoica, e seu lúmen inicialmente anecoico diminuiu gradativamente, sendo substituído por conteúdo hipoecoico com pontos hiperecoicos que, por fim, torna-se totalmente hiperecoico, assumindo as características de ligamento, uma vez que, ao final do processo de involução, é constituído por tecido fibroso, obtendo-se, assim, essa nova imagem ultrassonográfica. No estudo com bezerros Nelore, Sturion et al. (2013) não visualizaram a imagem do lúmen anecoico da veia após os 14 dias p.n.. No presente estudo, a diminuição da visualização do lúmen ocorreu da porção mais cranial da veia para a mais caudal, não sendo possível a visualização do lúmen na $\mathrm{P} 3 \mathrm{em}$ torno do $10^{\circ}$ dia p.n. e na P 1 somente entre o $20^{\circ}$ e o $30^{\circ}$ dia p.n., apresentando certa variação entre os animais. Assim como observado por Sturion et al. (2013), a parede da veia apresentou-se regular e contínua durante todo o seu percurso. Em alguns momentos, pode ser visualizada, no interior do vaso, aderida à parede, uma estrutura heterogênea, hipoecoica ou hiperecoica, possivelmente devido à presença de coágulos sanguíneos no interior da veia. Esses coágulos são caracterizados por apresentarem aspecto heterogêneo quando observados por ultrassonografia (Andrade Neto et al., 2011). 
Tais estruturas foram observadas nas veias somente a partir do terceiro dia p.n. e em apenas alguns dos animais avaliados, provavelmente em função do tempo levado para a formação dos coágulos.

Lischer e Steiner (1993) observaram reflexos entre a parede da veia umbilical e o seu lúmen, o que também foi visualizado neste estudo, não só nas veias, mas também nas artérias, sendo verificada uma linha hiperecoica entre a parede e o lúmen dos vasos. Essa constatação foi feita em várias posições e em diferentes momentos do presente estudo. A substituição do lúmen por uma aparência hipoecoica e, por fim, hiperecoica ocorre da parte mais externa do vaso, onde está a linha hiperecoica, para a mais interna. Muitas vezes, não foi possível caracterizar essa linha, principalmente nos dias próximos ao final do período de estudo, pois ela se tornava homogênea, confundindo-se com a ecotextura encontrada no interior do vaso. É possível, então, que essa linha hiperecoica indique o início da proliferação de tecido conjuntivo fibroso, que caracteriza o processo de involução dos componentes umbilicais. Ao final do período, o lúmen apresentava-se totalmente preenchido, não sendo mais possível visualizá-lo, e os componentes vasculares assumiram suas características de ligamento, caracterizando-se, então, a imagem do ligamento redondo do fígado.

Durante a exploração realizada no sentido dorsocaudal do abdômen, puderam ser obtidas as imagens das artérias umbilicais (Fig. 6 e 7). Foi possível visualizá-las próximas ao anel umbilical, na entrada do abdômen, com certa facilidade, durante todo o período do estudo, em contraposição ao observado por Lischer e Steiner (1993) e Watson et al. (2013), que não identificaram as artérias próximas ao anel umbilical, mesmo no primeiro dia p.n.. Nessa posição, as artérias apresentam a imagem semelhante à da veia umbilical com relação a sua ecogenicidade. Sua parede mostrou-se hipoecoica e conseguiu-se visualizar o lúmen anecoico até aproximadamente os 20 dias de vida dos animais. $\mathrm{O}$ lúmen foi diminuindo progressivamente e, tal como aconteceu com a veia umbilical, foi tornando-se hipoecoico, com pontos hiperecoicos, e, por fim, mostrou-se totalmente hiperecoico, no sentido da parede do vaso para o seu centro, até não ser mais notável.
Assim como Sturion et al. (2013) destacaram, essa visualização contraria o conceito de que, logo após a ruptura das artérias umbilicais, ocorre uma imediata retração desses componentes para o interior da cavidade, sendo possível observá-las somente próximas ao ápice da bexiga (Figuêiredo, 1999; Nuss, 2007). Nesta pesquisa, foi possível visualizar a imagem das artérias umbilicais em toda a extensão, desde o anel umbilical até a posição lateral da vesícula urinária. No entanto, essa visualização foi dificultada pela presença das alças intestinais, principalmente, quando essas se apresentavam com grande quantidade de gases. Adotar-se como referência a vesícula urinária tornou mais fácil a visualização das artérias umbilicais, que se encontram lateralmente a essa estrutura. $\mathrm{O}$ grau de repleição da bexiga também é um fator que contribui para a maior facilidade ou dificuldade desse exame. Quando a bexiga estava vazia, o exame foi mais difícil, pois perdeu-se o ponto de referência anecoico para a avaliação das posições P 6 direita e esquerda, sendo esse fato também constatado no estudo de Sturion et al. (2013).
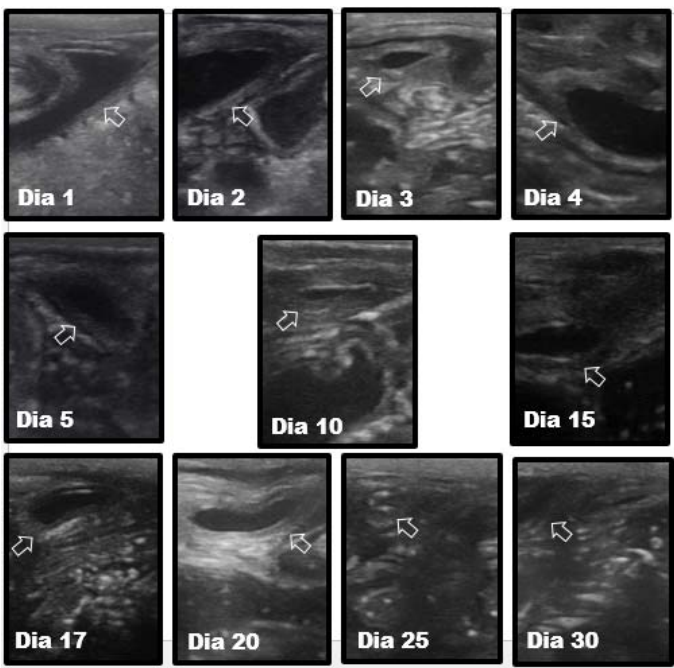

Figura 6. Acompanhamento ultrassonográfico da involução da artéria umbilical (setas), na posição 5, em bezerros Holandeses, do primeiro ao $30^{\circ}$ dia de vida. 


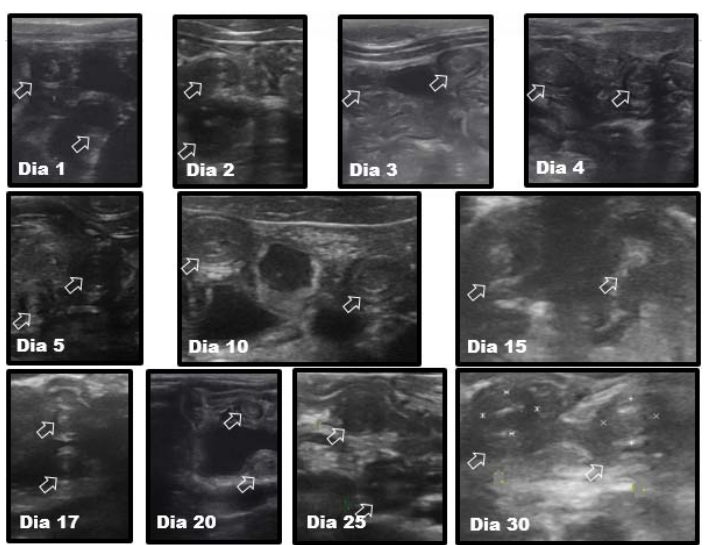

Figura 7. Acompanhamento ultrassonográfico da involução das estruturas umbilicais (setas indicando as artérias), na posição 6 , em bezerros Holandeses, do primeiro ao $30^{\circ}$ dia de vida.

Na posição $\mathrm{P} 5$, mais próxima à entrada das artérias no abdômen, estas apresentavam-se com parede hipoecoica e lúmen anecoico. Por sua vez, nas posições P 6, diferentemente do que foi observado por Watson et al. (1994), que destacaram lúmen discreto e anecoico, o lúmen foi observado inicialmente hipoecoico com pontos hiperecoicos. Entre o $15^{\circ}$ e o $17^{\circ}$ dia p.n., o lúmen foi visto com ecotextura homogênea, totalmente hiperecoico, apresentando-se com as características de ligamento. A parede das artérias, por sua vez, foi vista como uma estrutura hipoecoica, em concordância com as observações de Watson et al. (1994). Nos animais da raça Nelore, Sturion et al. (2013) visualizaram lúmen homogêneo e parede regular e hiperecoica. Nos primeiros dias de vida dos bezerros, nas, posição 6 , pode-se visualizar o lúmen das artérias com conteúdo hipoecoico a hiperecoico, fato verificado também por Sturion et al. (2013), que podem caracterizar a presença de coágulos sanguíneos, vistos no interior das artérias nestes primeiros dias p.n.

Além das artérias umbilicais, no feto, no sentido caudal é encontrado o úraco (Fig. 8), que se origina no ápice da vesícula urinária (Nuss, 2007), sendo a porção intra-abdominal dos vasos envolvida pelo peritônio (Figuêiredo, 1999). Durante o momento do parto, devido à contração e à pressão da musculatura abdominal, o úraco retrai-se para dentro da cavidade abdominal, rompendo-se e retraindo-se, passando a urina a ser totalmente excretada pela uretra (Figueirêdo, 1999). Sua involução ocorre de forma muito mais rápida que dos outros componentes, formando-se uma pequena cicatriz vestigial no ápice da vesícula urinária (Mccrystal et al., 2001).

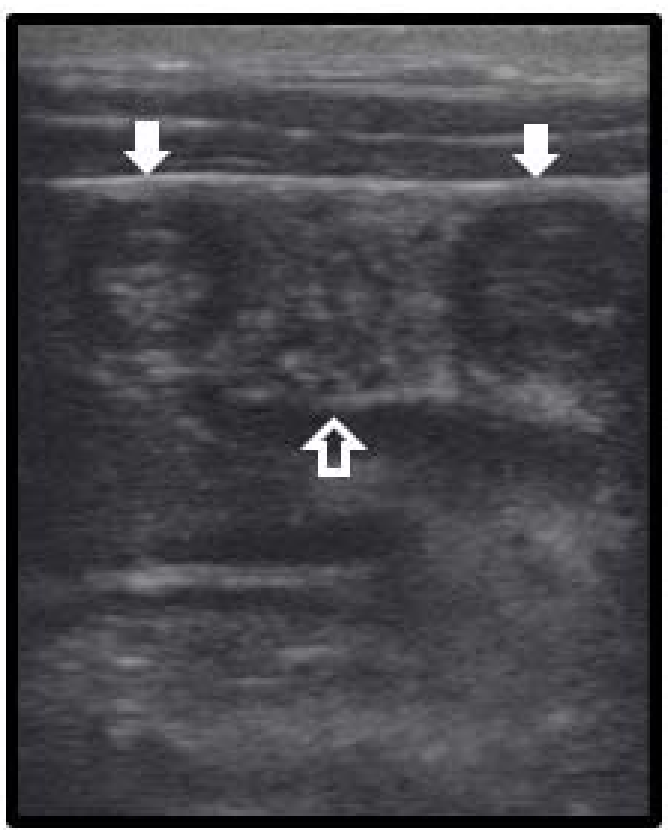

Figura 8. Imagem ultrassonográfica das artérias umbilicais (setas cheias) e úraco (seta sem preenchimento) na posição 6 , em bezerro da raça Holandesa, com três dias de vida.

O úraco geralmente não é identificado entre a região do coto umbilical e o ápice da bexiga (Watson et al., 1994). Ocasionalmente pode ser observado como uma estrutura hipoecogênica, cranial ao ápice da bexiga, e entre as duas artérias umbilicais. Ao se avaliar o ápice da bexiga, em alguns animais conseguiu-se observar o úraco, que pode ser visualizado no máximo até o quinto dia de vida. Dentre os animais estudados, dos 12 animais em que o ápice da vesícula urinária foi visualizado na primeira semana, foi possível observar o úraco em sete, entre as duas artérias umbilicais, sendo uma estrutura sem forma bem definida, com parede delgada e conteúdo hipoecoico com pontos hiperecoicos. Entretanto, o úraco não é facilmente diferenciado dos tecidos circundantes, além de seu lúmen não ser claramente definido, segundo Lischer e Steiner (1993). Buczinski (2002) afirmou que essa é uma estrutura de difícil visualização por meio do exame ultrassonográfico, mesmo no primeiro dia de vida do animal. Sturion et al. (2013) também 
relataram que essa estrutura é a mais difícil de ser avaliada, sendo possível, porém, sua visualização de forma clara até a primeira semana de vida dos animais da raça Nelore. Nos animais mais velhos, essa estrutura torna-se impossível de ser visualizada, em razão da redução de seu diâmetro (Sturion et al., 2013). Quando visualizada, possui parede mais delgada do que a da veia e das artérias, sendo a ecogenicidade de sua parede semelhante à da parede dos vasos (Sturion et al., 2013).

\section{CONCLUSÕES}

Os resultados indicam que a ultrassonografia é um excelente exame complementar para o diagnóstico das onfalopatias intra-abdominais nos bezerros, pois permite a completa visualização dos componentes umbilicais em grande parte dos animais. Assim, é importante o prévio conhecimento do aspecto das imagens ultrassonográficas durante cada fase de sua involução, o que possibilita o reconhecimento de possíveis alterações nos pacientes. Já que é possível localizar com exatidão o local de lesões em animais doentes, esse exame permite que se faça a melhor escolha de tratamento e um prognóstico mais favorável a esses animais.

\section{REFERÊNCIAS}

ANDRADE NETO, F. et al. Ultrassonografia nas massas anexiais: aspectos de imagem. Radiol. Bras., v.44, p.59-67, 2011.

ANDREWS, A.H. Calf management and disease notes. Hartfordshire: Nynwood Arts, 1983. 284p.

BENESI, F.J. Hematologia de bezerros recémnascidos. Influência da asfixia neonatal, do tipo de parto e da ingestão de colostro sobre a crase sanguínea. 1992. 126f. Tese (Livre Docência) Faculdade de Medicina Veterinária e Zootecnia, Universidade de São Paulo, São Paulo, SP.

BENESI, F. J. et al. Eritrograma de bezerros sadias da raça Holandesa, no primeiro mês de vida. Pesquisa Veterinária Brasileira, v. 32, p. 357-360, 2012a.

BENESI, F. J. et al. Leukogram of healthy Holstein calves within the first month of life. Pesquisa Veterinária Brasileira, v. 32, p. 352$356,2012 b$.
BUCZINSKI, S.M.C. Étude clinique de cas de pathologie ombilicale chez le veau comparaison de la palpation et de l'examen échographique. 2002. 72f. Thèse (Doctorat) Ecole Nationale Veétérinaire D'Alfort, Université Paris-est Creteil Val de Marne, Paris, FRA.

CRAIG, D.R. et al. Ultrasonographic diagnosis and surgical management of umbilical masses in calves. In: WORLD CONGRESS DISEASE OF CATTLE, 14., Dublin, 1986. Proceedings... Dublin: Irish Cattle Veterinary Association, 1986.

DIRKSEN, G. et al. Medicina interna y cirugía del bovino. 4.ed. Buenos Aires: Inter-Médica, 2005. p.618-625.

DIRKSEN, G. et al. Rosenberger - exame clínico dos bovinos. In: DIRKSEN, G. Sistema digestivo. Rio de Janeiro: Guanabara Koogan, 1993. p.166-228.

FEITOSA, F. L.; BENESI, F. J. Semiologia de Animais Recém-nascidos. In: FEITOSA, F. L. Semiologia veterinária: a arte do diagnóstico. 3 . ed. São Paulo: Roca, 2014. p. 69-97.

FIGUEIRÊDO, L.J.C. Onfalopatias de bezerro. Salvador: EDUFBA, 1999. p.31-34.

FLÖCK, M. Ultrasonic diagnosis of inflammation of the umbilical cord structures, persistent urachus and umbilical hernia in calves. Berl. Munch. Tierarztl. Wochenschr., v.116, p.211,2003

HYBERUILLE NETO. Maiores rebanhos bovinos em 2014. Bebedouro, SP.: Scot Consultoria, 2014. Disponível em: $<$ https://www.scotconsultoria.com.br/noticias/tod as-noticias/36510/maiores-rebanhos-bovinos-em2014.htm>. Acessado em: 06 abr. 2015.

LAENDER, F.C. et al. Alguns aspectos de manejo sanitário e principais doenças de bovinos. Tecnol. Agropecu. Bol. Tec., v.6, p.1$51,1984$.

LISCHER, C.J.; STEINER, A. Ultrasonography of umbilical structure in calves. Part 1: Ultrasonographic description of umbilical involution in clinically healthy calves. Schweiz. Arch. Tierheilkund., v.135, p.221-230, 1993. 
McCRYSTAL, D.J. et al. Acquired urachal pathology: presentation of five cases and a review of the literature. ANZ J. Surg., v.71, p.774-776, 2001.

NUSS, K. Erkrankungen der inneren Nabelstrukturen beim Rind. Tierärztl. Prax., v.35, p.149-156, 2007.

RADOSTITS, O.M. et al. Clínica veterinária. 9.ed. Rio de Janeiro: Guanabara Koogan, 2002. p.56-59.

REEF, V.B. Equine pediatric ultrasonography. Comp. Cont. Educ. Pract. Vet., v.12, p.12271285, 1991.

REEF, V.B. et al. Clinical, ultrasonographic, and surgical findings in foals with umbilical remnant infections. J. Am. Vet. Med. Assoc., v.195, p.6972, 1989.

REEF, V.B.; COLLATOS, C.A. Ultrasonography of umbilical structures in clinically normal foals. Am. J. Vet. Res., v.49, p.2143-2146, 1988.

RENGIFO, S.A. et al. Isolamento de agentes microbianos a partir de amostras de sangue e umbigo de bezerros mestiços neonatos. Braz. J. Vet. Res. Anim. Sci., v.43, p.442-447, 2006.
RIET-CORREA, F. Onfalite e artrite. In: RIETCORREA, F.; SCHILD, A.L.; MÉNDEZ, M.C. et al. Doenças de ruminantes e equinos. 3.ed. São Paulo: Livraria Varela, 2007. v.1, cap.3, p.199-443.

SEINO, C.H. Problemas umbilicais em bezerros nos primeiros 30 dias de vida: avaliação clínica, ultrassonográfica e correlação com a transferência de imunidade passiva. 2014. 100f. Dissertação (Mestrado) - Faculdade de Medicina Veterinária e Zootecnia, Universidade de São Paulo, São Paulo, SP.

STEINER, A. et al. A modified technique for the marsupialization of umbilical vein abscesses with involvement of the liver in the calf. A review of thirteen cases (1987-1990). Vet. Surg., v.3, p.184-189, 1992.

STURION, T.T. et al. Avaliação ultrassonográfica da involução das estruturas umbilicais extra e intracavitárias em bezerros sadios da raça Nelore concebidos naturalmente e produtos de fertilização in vitro. Pesqui. Vet. Bras., v.33, p.1021-1032, 2013.

WATSON, E. et al. Ultrasonography of the umbilical structures in clinically normal calves. Am. J. Vet. Res., v.55, p.773-780, 1994. 